\title{
What makes Darwinian hydrology "Darwinian"? Asking a different kind of question about landscapes
}

\author{
C. Harman ${ }^{1}$ and P. A. Troch ${ }^{2}$ \\ ${ }^{1}$ Department of Geography and Environmental Engineering, Johns Hopkins University, Baltimore, Maryland, USA \\ ${ }^{2}$ Department of Hydrology and Water Resources, University of Arizona, Tucson, Arizona, USA
}

Correspondence to: C. Harman (charman1@jhu.edu)

Received: 3 May 2013 - Published in Hydrol. Earth Syst. Sci. Discuss.: 23 May 2013

Revised: 25 November 2013 - Accepted: 11 December 2013 - Published: 4 February 2014

\begin{abstract}
There have been repeated calls for a Darwinian approach to hydrologic science, or for a synthesis of Darwinian and Newtonian approaches, to deepen understanding of the hydrologic system in the larger landscape context, and so develop a better basis for predictions now and in an uncertain future. But what exactly makes a Darwinian approach to hydrology "Darwinian"? While there have now been a number of discussions of Darwinian approaches, many referencing Harte (2002), the term is potentially a source of confusion because its connections to Darwin remain allusive rather than explicit.

Here we suggest that the Darwinian approach to hydrology follows the example of Charles Darwin by focusing attention on the patterns of variation in populations and seeking hypotheses that explain these patterns in terms of the mechanisms and conditions that determine their historical development. These hypotheses do not simply catalog patterns or predict them statistically - they connect the present structure with processes operating in the past. Nor are they explanations presented without independent evidence or critical analysis - Darwin's hypotheses about the mechanisms underlying present-day variation could be independently tested and validated. With a Darwinian framework in mind, it is easy to see that a great deal of hydrologic research has already been done that contributes to a Darwinian hydrology whether deliberately or not.

We discuss some practical and philosophical issues with this approach to hydrologic science: how are explanatory hypotheses generated? What constitutes a good hypothesis? How are hypotheses tested? "Historical" sciences - including paleohydrology - have long grappled with these questions, as must a Darwinian hydrologic science. We can draw on
\end{abstract}

Darwin's own example for some answers, though there are ongoing debates about the philosophical nature of his methods and reasoning. Darwin used a range of methods of historical reasoning to develop explanatory hypotheses: extrapolating mechanisms, space for time substitution, and looking for signatures of history. Some of these are already in use, while others are not and could be used to develop new insights. He sought explanatory hypotheses that intelligibly unified disparate facts, were testable against evidence, and had fertile implications for further research. He provided evidence to support his hypotheses by deducing corollary conditions ("if explanation A is true, then B will also be true") and comparing these to observations.

While a synthesis of the Darwinian and Newtonian approaches remains a goal, the Darwinian approach to hydrologic science has significant value of its own. The Darwinian hydrology that has been conducted already has not been coordinated or linked into a general body of theory and knowledge, but the time is coming when this will be possible.

\section{Introduction}

“... In effect, what an immense addition to our knowledge of the laws of nature should we possess if a tithe of the facts dispersed in the Journals of observant travellers, in the Transactions of academies and learned societies, were collected together and judiciously arranged! From their very juxtaposition, plan, co-relation, and harmony, before unsuspected, would become instantly visible, or the causes of anomaly be rendered apparent; erroneous opinions would at once be detected; and new truths - satisfactory as such alone, or 
supplying corollaries of practical utility - be added to the mass of human knowledge. A better testimony to the justice of this remark can hardly be afforded than in the work before us - Mr. Darwin's "Structure and Distribution of Coral Reefs" (Jackson, 1842).

The idea of a "synthesis of Darwinian and Newtonian worldviews" has been mentioned in a number of opinion papers (Sivapalan, 2003, 2005; Bloschl and Zehe, 2005; Beven, 2006; Kirchner, 2006; Newman et al., 2006; McDonnell et al., 2007; Wagener et al., 2010; King and Caylor, 2011; Kumar, 2011; Sivapalan et al., 2011b) and an increasing number of research papers (e.g., Sawicz et al., 2011; Cullis et al., 2012) as a response to a sense of crisis within the hydrologic community (Sivapalan, 2003, 2005; Bloschl and Zehe, 2005; Beven, 2006; Kirchner, 2006; Newman et al., 2006; McDonnell et al., 2007; Wagener et al., 2010; King and Caylor, 2011; Kumar, 2011; Sivapalan et al., 2011b; Wagener et al., 2013). The needs to predict and to understand watershed behavior in areas without long gauging records (Sivapalan, 2003) and under changing conditions (Sivapalan, 2012) requires new theories that go beyond the mechanics of runoff generation and focus on understanding the underlying climatic and landscape properties that control those mechanics (Sivapalan, 2005; McDonnell et al., 2007; Wagener et al., 2013; Thompson et al., 2013). Wagener et al. (2013) argued for the need for a "Darwinian" approach to prediction in ungauged basins, and discuss many of the concepts and approaches that have been given the term "Darwinian". Many of these visions cite Harte (2002) as an inspiration, who suggested that Earth systems science needs new approaches to dealing with the formidable difficulties of global change. He suggested that new approaches ought to find a synthesis of the disciplinary worldviews that dominate within physics (the "Newtonian" side) and ecology (the "Darwinian" counterpart). Elements of this synthesis would include simple, falsifiable models, the search for patterns and laws, and an embracement of "the science of place" - the in-depth examination of site-specific case studies.

So what is a "Darwinian" hydrology? The brief discussion by Harte (2002) does not provide a sufficiently detailed description of the Darwinian worldview to make the idea of Darwinian hydrology unambiguous. It may appear that "Darwinian" is equivalent to "ecological" and that what is being called for is simply to pay greater attention to the role of biological processes in the hydrologic cycle, or perhaps to incorporate natural selection into hydrologic models somehow. There is a danger that, unless clarified, the term "Darwinian hydrology" could be a source of confusion and misinterpretation. Darwin's work has itself been frequently misunderstood (often deliberately so) for more than $150 \mathrm{yr}$.

The approach to hydrologic science that has been called Newtonian is less ambiguous. There is a vast body of experimental, field, and modeling-based hydrologic science motivated by the desire to develop "physically based" models of hydrologic behavior derived from Newtonian first principles
- particularly the conservation equations. (The textbook of Brutsaert, 2005, provides a detailed overview of the results of these efforts.) These models attempt to capture the important processes that operate at the catchment scale (even though they implicitly assume that upscaling of processes is possible through effective parameter values) and drive the focus of hydrologic science toward finding the correct parameter values through observations, field experiments, and optimization algorithms (it is worth mentioning that these efforts bear little similarity to Isaac Newton's own practice of science).

We argue that Darwinian hydrologic science seeks answers to a complementary type of question about water and landscapes. Darwinian questions are less concerned with the mechanistic description of hydrologic process in isolation, and more concerned with explaining the hydrologic behavior of hydrologic systems as a whole. To some this may seem like no distinction at all - the behavior of the whole can be explained as the sum of the individual pieces. The difference comes from the nature of the explanation sought: a Darwinian account of a hydrologic system explains something about how those pieces came to be arranged in that particular way, as well as why they are similar or different across a population of watersheds. Far from being a radical or new notion, many elements of this approach can be found in published studies, though the importance and connection of these studies to this larger purpose may not yet be clear or appreciated.

This perspective on Darwinian hydrology is directly inspired by the work of Charles Darwin himself and can be illustrated by analogy to his body of work. To a number of evolutionary scientists, notably Ghiselin (1969) and Gould (1983), a key contribution of Darwin's work was his masterful way of doing "historical" sciences that connected observations of current forms with mechanisms and processes operating over time (much of what follows is drawn from these references and from "On the Origin of Species" (Darwin, 1859), "The Formation of Vegetable Mould through the Action of Worms" (Darwin, 1881), and "The Structure and Distribution of Coral Reefs" (Darwin, 1842)). These methods were not entirely unique or original to Darwin (see discussions by Ruse, 1975, and Thagard, 1977), but his is perhaps the finest and most masterful demonstration of their power over a broad range of questions. "Evolution by natural selection" was the theory that Darwin proposed to explain the present day forms and their variation. But to focus solely on that (transcendent) theory is to miss the potential contribution of his way of thinking to hydrology: the value of understanding how the variety, distribution, and contemporary function of hydrologic systems are determined by their historical evolution. Thus understanding might teach us much about their structure and function today, and their trajectories of change into the future. 
As Gould (1983) notes, the results of historical change "lie strewn around us", but the processes that produced them are not so easily observed. Connecting structure and history through mechanisms, Gould (1983) posited, is "the quintessential problem of evolutionary theory: how do we use the anatomy, physiology, behavior, variation and geographic distribution of modern organisms, and the fossil remains in our geologic record, to infer the pathways of history." Replace the reference to organismal characteristics with those of watersheds and hydrologic systems, and this is also a problem that Darwinian hydrology must face: how can we use the observable structure and function in populations of watersheds to infer the pathways of their history and the mechanisms that led to their present structure and function? This kind of historical science requires very different methodologies than those exemplified by physics. Replication, experimental controls, and reproducibility are unattainable standards for Darwinian hydrology. Different methods are needed.

To summarize, we propose that the Darwinian approach to hydrology is distinct from the Newtonian in the type of question it seeks to answer about the hydrologic cycle. Darwinian hydrology seeks to document patterns of variation in populations of hydrologic systems and develop theories that explain these patterns in terms of the mechanisms and conditions that determine their historical development. To achieve this, Darwinian hydrologic science needs methods for generating and for testing explanatory hypotheses. Lessons on how to do so can come from the historical sciences that Darwin drew on (such as geology, in which he was originally trained), and which have long wrestled with these challenges.

\section{The Darwinian approach}

We will develop these ideas in further detail by considering the example set by Darwin's own work. While the idea of evolution is today popularly regarded as Darwin's greatest achievement, this opinion is erroneous in two important ways. First, the idea that evolution occurred at all was a "common heresy" at the time and had been proposed by Darwin's grandfather Erasmus, amongst others (Gould, 1983). Secondly, it overlooks the revolutionary approach to scientific inquiry that Darwin developed not only in On the Origin of Species but throughout his whole career. It was Darwin's documentation of systematic geographic variations in species, his discovery and explanation of the mechanism by which evolution occurred, and the mountain of evidence that he amassed to support this mechanism that are the great contributions of On the Origin of Species.

\subsection{The type of question: anatomy vs. biogeography}

The defining feature of the "Darwinian" approach is the types of questions that we chose to address. In many points in his career (not just in the study of evolution), Darwin was concerned with the documentation and explanation of the spatial variations in individuals of similar types. To give one non-ecological example from Darwin's earlier work in geology, he proposed an explanation for the spatial distribution of coral atolls, fringing reefs, and barrier reefs (Darwin, 1842), for which alone he might have been justly renowned had his later work on species not overshadowed it. Threads of the same emphasis on the observation and explanation of variations in form connect across the many questions that Darwin addressed in his life.

Prior to Darwin, the question regarding species and their distribution was thought of very differently. Species were regarded as fixed types with an essential character that could be inferred by studying the anatomy of individuals of that type. This paradigm of essentialism was part of an intellectual tradition traceable to Plato's "ideal forms" - these ideas were widespread in every corner of intellectual inquiry at the time (Mayr, 1982). The scientific study of species tended to be largely concerned with documenting the essential characteristics of anatomy. For Darwin's contemporaries, like Louis Agassiz, the characteristics were the design of the creator and variations around the ideal were mere imperfections. Furthermore, the distribution of species around the world (and the apparent appearance and disappearance of species in the geological record) was explained by localized special creation and extinction, in accordance with that design. The presence of mammals in Asia and marsupials in Australia was a brute fact: to be documented, not to be explained. Biogeographic variations could be explained by post hoc rationalizations regarding the wisdom of the creator (who, wisely, gave polar bears white coats and forest-dwelling black bears dark coats).

Although initially Darwin accepted this paradigm, he came to be dissatisfied with it, since it provided no clear pathway for inquiry (Ghiselin, 1969). Instead he came to regard the variation of species in space and the variations of anatomy and habit within a species as both being of tremendous interest and importance. Darwin was a careful observer of the particulars of individual species' anatomy (indeed his mammoth treatise on the comparative anatomy of barnacles remains a benchmark of the field). However his theories on biogeography and evolution ultimately explained the variations within a species and between species. Darwin would not have developed such theories if his attention had been fixed on the observation of a single archetypal individual of a single species.

Compare these ideas to the study of watersheds. A large effort has been made to analyze the "anatomy" and "physiology" of watershed hydrologic systems, resulting in profound (but incomplete) insights into the spatiotemporal distribution of water storage and flux and the processes controlling runoff generation and water balance partitioning in individual watersheds. (It may be a stretch to regard such hydrologic processes as "Hortonian overland flow" and "saturation excess overland flow" as deriving from an essentialist impulse 
within hydrology - then again, it might not be. However, as Loague et al., 2010, point out, even though it is common to talk about these as distinct processes, it is not always possible to distinguish between them.) We are left with no satisfying capacity to understand, let alone to predict, how a particular watershed developed the hydrologic system it did. Consequently in hydrologic modeling and prediction we are clueless about constraints on parameter combinations that may result from the co-evolution of the catchment properties, such as the ecosystems, soils, and topography (Troch et al., 2013).

It should be emphasized that we are not only referring to the geomorphic development of the landscape over millions of years - watershed hydrologic behavior is the result of geomorphic, pedogenic, ecologic, and anthropogenic processes that operate over many timescales. While the disciplines that study these processes possess a deep understanding of the origins of landscape form, ecosystems, soils, and so on, it is hard to point to an equivalent body of knowledge about the origins of the hydrologic system as a whole, as it integrates across all these histories. Observations and modeling of hydrologic fluxes in a watershed model can provide insights into their interactions, but are not explanations of their own origins, in the same sense that the observation of a kangaroo's pouch cannot on its own explain the origins of marsupials in Australia.

What Darwin sought, and what a Darwinian hydrology can also seek, is an explanation of the origins of variations within populations. To do so, however, requires a type of "explanatory theory" that is quite different to the theory that is commonly used in hydrologic science. While we would regard the search for explanatory theories to be the defining feature of the Darwinian approach, this search will be in vain without appropriate methods for developing and testing them.

\subsection{The creation of explanatory hypotheses}

It can be difficult today to comprehend the mindset that was dominant prior to Darwin, in large part because of the pervasiveness of the intellectual revolution he created. To those steeped in the modern scientific era, "natural selection" can seem so conceptually elegant and simple an idea that it is a wonder that it took so long to be discovered. Darwin's insight has naturally raised the question for historians and scientists alike: what was it about Darwin's approach to scientific inquiry that was so special and led to such breakthroughs? For our purposes we can ask the question, what of Darwin's approach is transferable to the study of watersheds that we might make breakthroughs of similar importance (at least within the modest confines of hydrologic science)?

Ghiselin (1969) argued that Darwin's almost compulsive theorizing and hypothesizing is a key component of his success (despite his occasional public claims about being a "pure Baconian" inductionist; Ayala, 2009). The generation of a good hypothesis is perhaps the most mysterious component of the scientific method, Darwinian, Newtonian, or otherwise. The terms "abduction" or "explanatory inference" are sometimes used to refer to this type of inference, which is distinct from induction and deduction (Godfrey-Smith, 2003; De Waal, 2013). Given some surprising observation B, abduction is the generation of a prior condition $A$, such that if A were indeed found to be the case, B would be necessary and unsurprising.

It might seem that abduction is little more than guess work, but C. S. Peirce, the 19th century American logician and geophysicist, argued that it is a valid form of logical inference, since it allows us to proceed from unknown causes towards the truth. However, since there are an infinite number of logically possible causes, we must be able to hone in on those that provide better explanations than others. Various criteria can be employed: they unify the greatest number of surprising observations with a common cause, are compatible with past experience, provide fruitful implications that can be readily tested against observation, etc.

Many of the essential features of explanatory hypotheses, and the methods that can be employed to develop them, can be introduced through examples of the specific theories Darwin developed throughout his life. Gould (1983) argued that, over the course of his career, Darwin employed three broad strategies for generating explanatory theories: (1) measuring and extrapolating observable processes, (2) classification and space-for-time substitution, and (3) looking for the unique signatures of historical mechanisms embedded in present form. These are exemplified by his studies of earthworms (Darwin, 1881), of coral reefs (Darwin, 1842), and in the study of biogeography discussed at length in On the Origin of Species (Darwin, 1859).

\subsubsection{Measure and extrapolate the observable processes of change}

A profound insight that Darwin's theories relied upon was that the slow accumulation of small causes could have world-shaping effects if given enough time. This insight came to him through the revolutionary geological works of Lyell (1830). Darwin's final work on the formation of "vegetable mold" (which today is often called the O and A horizon of soils) summarized over $40 \mathrm{yr}$ of careful study of the habits and distribution of earthworms (Darwin, 1881). He collected quantitative data on the mass of worm casts, the frequency with which individual worms transport soil to the surface, and the density of worms themselves in the soil. He was thus able to establish a rate at which the whole mass of soil turned over ( 2 to $6 \mathrm{~cm}$ per decade). This analysis was not simply to document some peculiarities of worms but to present and test a hypothesis, namely that the soils of rolling, fertile hills of the English countryside were being constantly turned over with the action of earthworms. This churning explained a variety of other observations, including the smoothed form of the landscape, the tendency of stones placed in a field to sink over time, and for stone fragments in the regolith to form 
up in lines parallel to the surface. Thus, a range of observations were "explained" by the accumulation of the small yet observable - actions by worms. The "uniformitarianism" Darwin employed here should not be taken to exclude the possibility that profound change can come in sudden, dramatic events. It is well understood today that the pace of even biological evolution is not constant, but rather occurs in bursts that punctuate long periods of relative constancy (Gould and Eldredge, 1993).

\subsubsection{Classification and space-for-time substitution}

Where the processes involved in the formation of a phenomena are not directly observable (either because they happen so slowly or intermittently or because they have ceased altogether), a different approach is needed. In one of his first great achievements as a geologist, Darwin proposed a theory about the structure of coral reefs surrounding tropical islands (Darwin, 1842). He began with a classification of their forms that distinguished fringing reefs that occur on the shore; barrier reefs that are separated from the shore by a lagoon; and coral atolls, in which a ring of coral surrounds a lagoon without an island. These, he argued, represent a progression of forms that would occur if an island were thrust up from the sea floor and subsequently subsided or eroded away. The coral ring that begins as a fringing reef is preserved in the subsequent forms so long as the rate of sea-floor subsidence is slower than the maximum rate at which the coral can grow upwards. This space-for-time substitution argument is based on the assumption that similar phenomena (like reef formation) recur and follow similar "evolutionary trajectories" with different starting times. If disparate phenomena can be classified and arranged in this way from young to old, we can see through history.

Today radiometric dating techniques exist that can reveal whether different places do indeed represent a progression in time. However, Darwin's theory was widely popular even before such techniques were available because his theory is rich in corollary implications that provide critical tests of its validity. The outer sides of coral atolls should plunge steeply to the sea floor. Atolls should be rare or absent in areas of uplift. In areas of rapid subsidence we should find remnant towers of coral that grew too slowly and were drowned. The theory was accepted not simply because this time-for-space substitution provided a coherent story uniting a set of observations, but because it made specific predictions that have been subsequently confirmed by other observations.

\subsubsection{Look for unique signatures of historical conditions}

Darwin accumulated evidence for or against an explanatory theory even if processes could not be measured directly or if the uniqueness of each individual defied classification. Even before developing the theory of natural selection to explain how species change over time, he had developed a sophisticated theory explaining biogeographic variations in species distribution based on their dispersal mechanisms and the way geological change created (or removed) barriers to dispersal. During his voyage on the Beagle, Darwin observed that amphibians (whose eggs can only survive in freshwater) are entirely absent from Pacific islands, and that the only mammals present are flying bats. Darwin experimented on seeds to see which could survive long periods submersed in seawater or passing through the guts of birds. He was able to show that the assemblage of species in a place depended on the particular history of barriers to species reaching that place (such as oceans or mountain ranges) and the particular mechanisms available to those species for crossing those barriers (by flight, migration over land, or rafting across the ocean).

Darwin's theory of biogeography was developed by finding a coherent explanation for a wide variety of facts about a particular place that relied - as much as possible - on only those facts that could be observed or determined experimentally. It is an approach that acknowledges the unique history that has controlled the development of each place (whether geology or colonization) without giving up on the ability to construct an explanation whose features are transferable between places. In this case, transferability comes from the ability of the theory to suggest where to look when constructing an explanation of a unique place: towards the formation of migratory barriers and the propagation and dispersal capacities of species. Such a theory in hydrology would overcome the problem of "uniqueness of place" discussed by Beven (2000) without denying or simplifying the complex unique characteristics of watersheds.

These three "heuristics" suggest ways of abducting hypotheses within the Darwinian approach. All share the characteristic that they seek to explain observed variations in form and function in terms of historical mechanisms and in ways that are transferable between places. Furthermore, these approaches suggest methods for testing them against further observation.

\subsection{Testing explanatory hypotheses}

It is clear that the controlled, replicated experiments that characterize other forms of science cannot usually be employed to test explanatory theories (Cleland, 2002). In general such theories do not make predictions in the same sense that a Newtonian "law" does - they aim only to explain the observations already made. So how can such theories be tested, given that we are unable to "rewind the clock" and watch the evolution of organisms, coral reefs, or watersheds directly? This problems is ubiquitous in those Earth sciences that aim to explain origins (including geomorphology and pedology), and the examples above show that they were of great interest to Darwin.

Ghiselin (1969) argued that Darwin's approach to testing and confirming his theories fits the mold of what has 
been called the "hypothetico-deductive" approach. This can be approximated as four steps: (1) collect extensive and detailed observations of the pattern to be explained, (2) conceive a hypothesis that accounts for as many of the observations as possible, (3) derive from this hypothesis a consequent set of circumstances that must also hold if the hypothesis is true (this is the step that gives the method its name), and (4) critically test whether these consequences do hold. This approach blends the epistemological approaches of induction (step 1), abduction (step 2), deduction (step 3), and falsifiability (step 4). Kleinhans et al. (2010) have also argued for the combination of these approaches for developing "explanatory models" in experimental hydrologic science that explain the general phenomena under consideration rather than make specific predictions as accurately as possible.

Philosophers of science have questioned the hypotheticodeductive approach, asking whether derived consequent conditions really can provide confirmation of the original hypothesis (see Godfrey-Smith, 2003, for an overview of these issues). We must also tread with caution in applying formal philosophical ideas to Darwin that did not find expression until well after his death (such as Popper's concepts of "falsifiability"). Many works discussing approaches to testing explanatory theories can be found amongst the Earth science and philosophical literature (Gilbert, 1886, 1896; Chamberlin, 1890; Von Engelhardt and Zimmermann, 1988; Schumm, 1991; Frodeman, 1995; Baker, 1996a, 1999, 2000, 2012; Cleland, 2002, 2011, 2013). We direct the reader to these references for a more nuanced discussion than we can provide here.

The hypothetico-deductive method also neglects a key test on the hypotheses that was vitally important to Darwin. To him, the need to postulate entities or events for which there was no independent evidence was a fatal flaw in the theories of his contemporaries. This principle extended beyond his rejection of special creation where its application is obvious. Many of Darwin's contemporaries invoked the appearance and disappearance of land bridges (that allowed animals to migrate from continent to continent) to explain anomalies in the biogeographic distribution of species. Darwin saw these as theoretical luxuries for lazy scientists, and he insisted on devising and testing his theories on the basis of the present configuration of continents (Wegener's theory of plate tectonics was still decades away).

Recently, physicist David Deutsch made a similar argument that a central quality of a good explanatory theory is that its conditions are "hard to vary" without the whole argument collapsing - conditions cannot simply be added or removed (like hypothetical land bridges) in the face of contradictory facts (Deutsch, 2009). Thus a proposed explanatory theory supersedes an existing one if it can explain more facts with fewer conditions. The most compelling evidence for natural selection in On the Origin of Species (Darwin, 1859) came largely from its ability to explain variations between species (including biogeographic variation) better than any competing theory and do so in a way that was rich in implication (Ghiselin, 1969). Note that Darwin's theory was not built around a theory of genetics, as he was unaware of Mendel's theory of inheritance - the arguments for evolution were not built on "first principles" but rather on empirical observation. Exceptions and anomalies are inevitable; no theory will be able to explain all the observations perfectly, and such exceptions should not be merely accommodated by the invocation of causes without evidence. Exceptions to a rule demand their own explanation and drive the search for better theory.

These characteristics - the ability to connect disparate facts, to be testable and falsifiable, and to lead to new horizons for further research - make the Darwinian explanatory theories useful and valuable, despite their limited ability to make precise "Newtonian" predictions.

\section{A Darwinian approach to watershed science}

Darwin's methods suggest an approach to hydrologic science that differs from the Newtonian approach in the kinds of questions it asks about landscapes and in the tools used to answer those questions. We will discuss what that approach might look like here, but restrict our discussion mainly to watershed hydrology. The Darwinian approach aims to provide an explanation - derived from the historical co-evolution of the landscape and the legacies of the past over many timescales (from geological to human) - for the patterns of variation in hydrologic behavior within a population of watersheds. This explanation must elucidate a mechanism that has created that variation and generate corollary statements about the landscape including, but not exclusive to, its hydrologic behavior that can be tested against evidence. To be judged superior to competing hypotheses, this explanation must account for more variation with fewer contingencies and exceptions.

It might be argued that the science of paleohydrology represents a branch of hydrology that is already applying these principles to hydrologic questions (see Schumm, 1967; Baker, 1996b, 1998). The reconstruction of paleofloods and megafloods might be analogous here to the fossil record that Darwin drew on to provide evidence for his theories. However, most of hydrologic science is focused on today's watersheds and their hydrology, and is disconnected from recent advances in paleohydrology (Benito and Thorndycraft, 2004; House et al., 2002; Baker, 2006, 2008, 2013a). Even so, with concepts described above in mind, it is not hard to find examples of recent hydrologic studies that contribute towards Darwinian hydrologic theory, even where that goal is not articulated. In the discussion below, some of these will be highlighted, though a comprehensive review must be left for another time. 


\subsection{Hydrologic variations in populations of watersheds: regimes, filters, and functional patterns}

What are the patterns of hydrologic variability that a Darwinian approach aims to explain? Darwin was able to measure and compare the properties of organisms (such as the length of a finch's beak), but it is not so simple to define the hydrologic "form" of a watershed, let alone compare these forms in a consistent way between watersheds. Comparing the hydrology of two watersheds distant from each other on the basis of (for instance) only their streamflow today is of very little interest - the Newtonian physically based models are better suited to "explaining" why one may have greater flow than the other in terms of the antecedent conditions and recent rainfall. The response of a watershed to a single storm event does little to reveal the hydrologic "anatomy and physiology" of a watershed. A Darwinian approach to hydrology might better try to explain hydrologic variability viewed with a broader perspective in terms of hydrologic regimes, filters, and functional patterns.

\subsubsection{Variation across time: regimes and filtering}

The (broadly speaking) statistical distribution of hydrologic states and fluxes over a larger time- and space scale has been referred to as a system's regime (Pickup and Warner, 1976; Mosley, 1981; Magilligan and Nislow, 2005). This structure has been investigated through the prism of signatures including the flood frequency curve (e.g., Robinson and Sivapalan, 1997), water balance partitioning (Troch et al., 2009; Harman et al., 2011; Sivapalan et al., 2011a), flow duration curve (Coopersmith et al., 2012; Yaeger et al., 2012; Cheng et al., 2012; Ye et al., 2012), recession curve (e.g., Wittenberg, 2003), preferred states in the soil moisture distribution (e.g., Western and Grayson, 2001), and seasonal variations in the fluxes measured at an eddy-flux tower (Thompson et al., 2011). The study of regimes adopts the Darwinian approach of analyzing populations but in the temporal domain (understanding a population of events within a watershed).

It might be argued that hydrologic regimes are largely determined by climate, leaving little variation left over to be "explained". Indeed the studies cited above show that climate is the major control on most of the signatures of catchment regime. However, this control is expressed in two different ways: directly, through the water and energy drivers of the water balance, and indirectly as one of many controls on the evolution of the landscape's hydrologic properties. Methods have been (and continue to be) developed to extract the net effect of these properties at the watershed scale from the observed hydrologic signatures (e.g., Wittenberg, 1999; Jothityangkoon and Sivapalan, 2009; Kirchner, 2009), many derived from the notion of a "top-down" approach to conceptualizing hydrologic systems (Klemeš, 1983; Sivapalan et al., 2003). By separating the direct effects of climatic variability from the "filter" that transforms that variability into the hydrologic regime, these methods can reveal watershed hydrologic properties explicable in terms of their history, including the indirect effects of climate (e.g., Troch et al., 2013). The analysis of the passive tracer and biogeochemical "filtering" extends this type of integrated-scale analysis (e.g., Guan et al., 2011). Schröder (2006) suggested a parallel kind of filtering in the way environmental factors "filter" ecosystem species composition according to their traits.

While data on hydrologic fluxes are essential to quantifying these regimes, reliable observations of fluxes at watershed scales are limited to streamflow, though estimates of precipitation, in particular, are improving. Because of this limited window, watershed models have been relied on to "fill in" the unobserved data and provide a richer view of the hydrologic regimes. For instance, Carrillo et al. (2011) used a model calibrated to hydrologic signatures in 12 watersheds to extract a set of timescales that controlled different sets of storage and partitioning processes, such as the duration of infiltration at the average storm rainfall rate that would be required to fill the unsaturated zone and initiate deeper drainage. Expressing catchment characteristics in terms of timescales helped reveal how the variations in those characteristics between watersheds determine variations in watershed regimes.

There are challenges to using hydrologic models for examining regimes and filtering, as models inevitably incorporate a priori assumptions about the nature of the controls and the way to express these controls in a mathematical model. The regimes of internal fluxes and states are therefore dependent on the assumed model structure and on the parameters obtained by calibration. As Beven (2000) and many others have discussed, the problems of equifinality and parameter identification limit our ability to use models to resolve the unique character of individual watersheds. Poor model structures can rarely be discriminated on the basis of the available hydrologic data, let alone identification of the "best" structure and parameter set to represent the watershed. It has been suggested that rather than producing a sharp image of the unique hydrologic regime of a specific watershed, inversion from hydrologic data can only reveal an ill-defined cloud of regimes that corresponds to the subset of models that have been judged "behavioral" within the space of possible models (Beven, 2000). Limitations on our ability to directly observe hydrologic storage and flux at both high spatial and temporal resolution and large spatial extent therefore mean that we are left with a "blurry", uncertain image of watershed anatomy and behavior. New data sources, such as from remote sensing and hydrogeophysics, will hopefully allow these images to be sharpened in the future.

\subsubsection{Variation across places: functional patterns}

The greater potential of the Darwinian approach may be to explain and even predict the patterns of variation in regimes and filtering across watersheds (and perhaps over time). The 
importance of "comparative hydrology" for advancing hydrologic understanding and theory has been discussed for many years (Falkenmark and Chapman, 1989). Patterns in the regimes and filtering of many watersheds across climatic, geologic, and ecologic gradients have been called "functional patterns" (Sivapalan, 2012), since they suggest emergent functional interdependencies between hydrologic behavior and the landscape properties that control them.

We can highlight two fundamental and illustrative examples of the kind of functional pattern in the regimes of watersheds that might be explained by the Darwinian approach: (1) variations in average annual water balance partitioning and (2) variations in runoff process dominance.

\section{Water balance}

The Budyko curve, popularized by Budyko (1974), plots the fraction of average annual precipitation $(P)$ that leaves the watershed as evapotranspiration $(E)$ against the ratio of energy available to drive evapotranspiration (Ep) and available water $(P)$. When data from many watersheds are plotted together on this curve, variations in this hydrologic partitioning of annual precipitation into runoff and evapotranspiration in natural watersheds are limited to a curve near the upper envelope of possible values constrained by the available water and energy. There is no (Newtonian) constraint that prevents the population of watersheds from completely and randomly filling the space within the envelope defined by these conservation constraints. The fact that they follow some sort of curve, even with considerable scatter, suggests that the associations between the controls on water balance are not random but are a signature of the climate and development of the landscape.

This curve has been examined by a number of modeling and observational studies (Milly, 1994; Zhang et al., 2001; Atkinson, 2002; Farmer et al., 2003; Porporato et al., 2004; Donohue et al., 2007; Yokoo et al., 2008; Gentine et al., 2012; Troch et al., 2013) that have elucidated the first-order controls on this partitioning. These suggest that for a given ratio of $\mathrm{Ep} / P$ the variation between watersheds (that is, the scatter around the curve) is largely controlled by a number of factors that can be summarized as follows:

- The temporal variability of inputs of precipitation and energy, including the phasing of the seasonal variability in rainfall and energy, the frequency and intensity of storm events, and their tendency to cluster in time.

- The capacity of the landscape to store these inputs (in canopy interception, soil, perched water tables, and deeper groundwater) and delay their delivery to the watershed outlet.

- The ability of vegetation to access this stored water during periods of high atmospheric demand through root water uptake.
At the extreme upper envelope bounding the Budyko curve are watersheds where seasonality in energy and water inputs directly covary, storage capacity is high, and vegetation is always able to access the needed water. At the lower boundary (along the horizontal axis) are watersheds where rainfall occurs at times when there is little energy to drive evapotranspiration, storage capacity is low and water runs off quickly, and that water which is stored is unavailable to vegetation.

Understanding these controls on the water balance partitioning is not trivial and continues to be an active area of research. The clarification of hydrologic controls on waterbalance partitioning is a step towards an explanatory theory of why those controls vary between landscapes and towards the further goal of predicting variation between places. Such a theory would provide answers to fundamental questions such as these: why does a particular watershed have the storage capacity that it does? How has the geologic, pedogenic, and geomorphic - and indeed hydrologic - history of that landscape determined that capacity? Recent attention to the role of storage in watersheds (McNamara et al., 2011; Tetzlaff et al., 2011) has typically avoided the question of how and why that storage exists.

\section{Process dominance}

Runoff generation mechanisms are generally conceptualized as Hortonian infiltration excess, "Dunne"-type saturation excess, and subsurface stormflow. The tendency of a watershed to be dominated by one mechanism over another is a function of the physical properties of the landscape and the climate, and understanding these controls is central to obtaining the "right answers for the right reasons" (Kirchner, 2006). Measurement and modeling can be used to determine which processes control runoff generation in a particular watershed, but there is little in the way of theory to make quantitative predictions about variations in process dominance between watersheds.

Dunne (1978) attempted to synthesize, in a qualitative way, the controls on runoff generation process dominance at the hillslope scale. The "Dunne diagram", as it has come to be known, proposed that in dry or human-impacted watersheds, the Hortonian mechanism dominates, while in more humid and densely vegetated areas, runoff generation depends more strongly on topography and soils. In steep areas with permeable soils, subsurface stormflow is the dominant mechanism, while in low-gradient areas with concave footslopes, saturation excess is most important.

Despite the influential nature of this conceptualization of the patterns of variation in runoff generation between watersheds, there have been few attempts to either arrive at a more precise, quantified form of it or to develop a theory that explains why these systematic variations in process dominance occur. As with the Budyko curve, there is no reason why naturally developed watersheds should cluster into these patterns - a human-created asphalt car park in a wet climate can 
violate both the Budyko curve and the Dunne diagram without violating conservation of mass, energy, and momentum. That non-human-created watersheds show such a pattern of behavior is a pattern that must be explained using tools that go beyond fluid mechanics or soil physics.

\subsection{A Darwinian explanatory hypothesis for watersheds in dynamic landscapes}

A Darwinian explanatory theory is necessarily tentative, yet provides a clear picture of why variations in the regimes or filtering observed in a region exist. For example, recent work by Lohse and Dietric (2005) (see also Lohse, 2002) and Jefferson et al. (2010) suggests that such a coherent explanatory hypothesis can be developed to account for changes in hydrologic function along an "evolutionary pathway" of basaltic rocks in Hawaii and in the Oregon Cascades. Each study made detailed observations in watersheds formed on lava flows ranging in age from the Holocene to more than 1 million years old. In both sites the evidence suggested that the young landscapes were initially drained vertically through the bedrock and into groundwater and thus groundwater discharge was significant. At older sites the soils became increasingly weathered, producing illuviated clay horizons, which tended to reduce vertical infiltration and promote lateral redistribution. This shift in hydrologic process dominance has been hypothesized to be accompanied by an increase in the drainage density and landscape evolution (Lohse and Dietrich, 2005; Lohse, 2002). Jefferson et al. (2010) noted a systematic decrease in the baseflow index and increase in drainage density as watersheds aged.

These studies point toward a hypothesis about the ways that hydrologic processes evolve over time under wet climates with specific geologic initial conditions (basalt lava flows). A more general hypothesis could be framed to account for the functional patterns observed across many such landscapes, such that the frequency with which a given combination of watershed characteristics is observed reflects (1) the frequency that the initial conditions leading along an evolutionary pathway to that combination is created (in the above case, the historical frequency of lava flows over time) and (2) the relative rates of change of landscapes in different configurations (which appears to slow down over time in the case of Jefferson et al., 2010). For convenience we will refer to this hypothesis as the REI (rate of evolution and initialization) hypothesis.

The first part of this hypothesis reflects the requirement that the present hydrologic configuration of the landscape must be "reachable" in the state space of possible hydrologic configurations that evolve as a result of the available geomorphic, ecologic, pedogenic, and anthropogenic processes. The second suggests that the relative frequency with which a particular combination of watershed characteristics is observed (given some constraints of climate and geology) is influenced by the relative duration that such a combination of parameters can persist in the face of geomorphic, ecologic, climatic, and even human processes of change.

REI is an elementary hypothesis, derived from the assumption that some combinations of hydrologic properties are inherently unstable and prone to rapid shifts (geologically speaking) towards more stable states. Other combinations are more stable, in the sense that they persist for a longer period of time. This assumption is supported by ideas regarding the persistence of and convergence towards geomorphic "forms" (Brunsden and Thornes, 1979) and the resilience and stability of ecosystems (Tucker and Hancock, 2010), both of which posit that there are system configurations that persist while others are transient. The stable configurations of landscapes need not be static or even steady state under this assumption - they need only to have combinations of process dominance and water-balance partitioning that change more slowly over time than other combinations.

Thermodynamic "optimality" constraints have been suggested as a basis for predicting watershed behavior (Kleidon and Schymanski, 2008; Schymanski, 2008; Schymanski et al., 2009), under the hypothesis that watershed organization represents a configuration that optimizes a thermodynamically defined condition. The REI hypothesis makes fewer assumptions than the thermodynamic optimality hypotheses but is potentially compatible with them. That is, it is possible that the combinations of watershed properties that produce the most rapid change may be those that are furthest from the optimal conditions. Conversely, the most persistent states may reflect an asymptotic approach to the optimal condition or possibly an optimal condition perturbed by disturbance, rather than the optimal itself (such as where frequent fire in grasslands prevent recruitment of trees, even though from some water-use perspectives, they might be closer to an optimal condition). However, optimality is not a necessary outcome.

The REI hypothesis is also appealing in part because of its resemblance to statistical mechanics, which can predict the aggregate properties of a population of molecules in a gas (like temperature) in terms of the most likely combination of particle states. Along these lines, we could express the hypothesis equivalently as proposing a sort of "ergodicity" in landscape: that the frequencies with which a set of combinations are observed in a region (that is, when watersheds with similar climatic and geologic properties are compared) are related to the frequency with which they occur and to the duration that they persist in time (that is, when the evolutionary history of a single watershed is considered). Combinations that can persist only for a short period of time (or are the transient consequence of an infrequent disturbance) are less common today than those that persist for a long time (or arise from a frequent type of disturbance).

As it is stated here, REI is a very general hypothesis and needs considerable development to meet the standards of a Darwinian explanatory theory. However, it does have the necessary characteristics of such a theory, as described above. 
It connects across disparate facts by proposing a connection between geomorphic and ecologic landscape stability and the frequency of different regimes of hydrologic variability and process dominance. It is testable, in that the relationship between relative stability and relative frequency can be compared, at least in principle. This comparison will be challenging in practice. Finally, it motivates new approaches to develop and test this type of Darwinian theory.

\subsection{Developing and testing explanatory hypotheses in watershed hydrology}

So how could the methods that Darwin used to develop and test his explanatory theories be applied to watershed hydrology to test explanatory theories like the (very general) one presented above? The three methods Gould (1983) described served as fruitful avenues for research, and thus are worth exploring in more detail.

\subsubsection{Extrapolating mechanisms: co-evolution modeling}

Advances in geomorphic modeling in recent years (Roering et al., 1999; Dietrich et al., 2003; Pelletier and Rasmussen, 2009) have connected process controls on sediment redistribution to larger-scale landscape structure. As these theories have matured, they have naturally enough become increasingly linked to models of soil and ecosystem development and to the climatic drivers (Paola et al., 2006; Hancock et al., 2011; Pelletier et al., 2013). For example, Heimsath et al. $(1997,2005)$ connect soil and landform development to provide mechanisms that simultaneously "explain" the variations in hillslope curvature and soil thickness between landscapes (Roering, 2008). Many of these theories are based on a philosophy articulated in Dietrich et al. (2003) that aims to develop process representations that have measurable parameters, make specific predictions (such as the form of a slopearea relationship) that can be tested against observation, and are applicable at the scale of the problem - that is, the timeand space scales relevant to the formation of landscape morphology. This type of approach can also be found in the concept of "pattern-oriented modeling" in ecology (Grimm et al., 2005), which seeks to explain multiple ecosystem-scale emergent patterns in terms of rules governing the behavior of individual agents within the ecosystem, and test these in terms of the corollary implications of those rules.

Models that aim to predict the co-evolution of the hydrologic "morphology" of landscapes - the regimes and the functional patterns between places - might have a similar set of aims. Rather than being used to predict the future evolution of landscapes or reproduce the precise form of a particular landscape, these models allow for testing of hypotheses to do with the relationship between the cumulative effects of processes interacting over time and in space. As Thompson et al. (2013) suggest, this co-evolution modeling is not limited to landform and soil evolution over geologic timescales but can also include the development of ecological and human coupled systems, if the appropriate parameterizations can be developed and properly tested. Such models could help evaluate the "reachability" requirement of the Darwinian hypothesis and quantify the relative duration of different configurations of landscapes. There are great challenges to be overcome in finding the appropriate ways to represent the feedbacks between hydrology and other longer-term landscape processes and in the parameterization of these relationships from observations, but progress is being made (Hopp et al., 2009; Tucker and Hancock, 2010). For example, Pelletier et al. (2013) recently circumvented these feedbacks by connecting effective process parameters to a higher-order variable (effective energy and mass transfer - EEMT) that captures water and energy constraints on landscape-forming processes and used this to explain variations in topography, soil thickness, land forms, and biomass across a climate gradient in southern Arizona.

\subsubsection{Space for time: a genetic classification of watersheds}

Darwin's theories generally did not make predictions about the fates of individuals, but instead focused on the behavior of populations of similar types - finches, coral reefs, or soils. The theories themselves were necessarily interdependent on the method of classifying those types in a useful way. Hydrologists have also been working to develop a classification system that can provide useful information about catchment function (McDonnell and Woods, 2004; Wagener et al., 2007). Many of these classifications are derived from the hydrologic behavior itself, either through analysis of characteristic signatures of rainfall and flow variability (Sawicz et al., 2011) or through bottom-up analysis of watershed hydrologic function using simple models (Carrillo et al., 2011). Others classify watersheds within a region on the basis of ecological, climatic, geologic, and land-use characteristics under the assumption that these will be the primary controls on hydrologic function (Winter, 2001; Woods, 2004).

These approaches highlight functional patterns and distinguish between watersheds that behave in fundamentally different ways (snow-dominated versus monsoonal, for example). They may provide breakthroughs to advance predictability in ungauged basins. However they do not yet perform the same function that Darwin's classifications did. Classifications based on observable characteristics can be described (to borrow a term from biological taxonomy) as phenotypical - they sort watersheds on the basis of present-day expressed morphology.

In contrast, Darwin's explanatory theories of coral reefs and organisms were built on a classification system that collected together functionally similar entities in a way that also grouped them in terms of their evolutionary origins. In modern terms, this connects the phenotypical classification to 
classification on the basis of a common historical development (genotypes). This type of genotypical classification is tightly linked to the explanatory theory. In principle, since there are many ways to classify (say) coral reefs, there is no reason to divide them into atolls, fringing reefs, and barrier reefs (as opposed to some other grouping). However doing so immediately reveals a pattern in space connected to the rates of sea floor uplift and subsidence that caused those forms to occur. The ability of the explanatory theory to provide a unity of phenotypical and genotypical classifications contributes to the theory's success. More recently, plant ecologists have developed classifications based on functional "traits". They distinguish "response traits" - characteristic responses to environmental events - from "effect traits": characteristic effects on other parts of the ecosystem (Schröder, 2006). Not only can these traits be understood in terms of evolution at an organismal level but ecologists also hope that they can form the basis of a theory capable of explaining (and predicting) changes in community composition and ecosystem function over time (Lavorel and Garnier, 2002; Suding and Goldstein, 2008).

A hydrologic classification of a similar type could be linked in the same way to an understanding of the type of evolutionary progression that produced it. Watersheds that have similar histories and have converged through coevolution into a similar set of characteristic behaviors would be grouped closer together (such as those that bear a strong signature of recent glaciation or those formed by the continuous adjustment of hillslope colluvial processes to changes in base level). Similarly, two watersheds whose hydrologic behaviors are superficially similar but arise from a very different set of histories (in the sense of "convergent evolution") would be grouped separately (as dolphins and fish are). This type of classification would enrich the picture of process dominance developed by Dunne (1978) by providing a hypothesis about the connection between the spatial patterns of process dominance and the progression of hydrologic forms a landscape passes through as it evolves.

\subsubsection{Signatures of history: looking for evidence of general laws in detailed case studies}

Just as Darwin's theory of biogeography did not make specific predictions about what the species of a place would be, but rather about "what to look for" when investigating a specific place, so can a Darwinian hydrologic theory help determine what types of historical events might be of significance in shaping the contemporary hydrology of a watershed. For instance, Bain et al. (2012) have described the importance of appreciating historical legacies when interpreting landscape properties and estimating material flux rates in study sites. They caution that in many parts of the eastern US, estimates of "background" sediment flux rates from long-term studies may be biased by the legacy of structural changes in the landscape that followed European settlement but preceded the initiation of long-term monitoring.

Where neither rates of processes could be reliably quantified nor classification and space-for-time substitution used to provide insight, Darwin's detailed case studies provided a weight of evidence to support his general hypotheses. Within hydrology there are now a large number of watersheds that have been studied and characterized "in depth". Attempts at synthesizing these into a single framework have had only partial success. A corollary of the REI hypothesis suggested here, testable by such case studies, is that the configurations that produce water-balance relations far from the Budyko curve or combinations of process dominance in contradiction with the Dunne diagram are either unstable configurations or configurations that are slow to change but rarely occur. For example, landscapes in humid climates whose soils induce rapid overland flow are hypothesized to undergo rapid geomorphic change. Such landscapes do exist, such as the Pink Cliffs near Heathcote in Victoria, Australia, where human disturbance (in the form of hydraulic sluicing during the gold rush period) perturbed the previous soil landscape configuration and exposed the weathered granite bedrock beneath. This area is now a rapidly eroding badland and will quickly (geologically speaking) disappear from the landscape. Similarly, vegetation quickly transforms areas where water is a limiting factor and is underutilized, even if disturbance or other factors prevent systems from obtaining an "optimum" configuration.

\section{Conclusions}

\subsection{The promise of a Darwinian approach}

We have argued that the methodological approach of Charles Darwin can provide lessons for the development of a "Darwinian" approach to hydrology. This approach is by no means a "panacea" to all the challenges hydrology faces, but could lead to new fundamental and practical insights. We have argued that the central purpose of the Darwinian approach is to provide a clearly expressed body of theory that explains the formation, and adjustment through time, of the patterns expressed in hydrologic systems.

The crucial step that Darwin made was to study not merely the physiology of individual species but to seek explanations for the variations in physiology through space and time in terms of their natural history. We argue that the study of populations of watersheds, and the search for an "explanatory theory" that connects their current similarities and differences to the processes that created them, is an essential aim of a "Darwinian" approach to hydrology. As Kleinhans et al. (2010) put it recently, "in geology and biology an explanation for a phenomenon is not complete without reference to both physical factors and history". We have argued that the explanatory theories put forward to account for the functional 
patterns in hydrologic regimes and filtering must be critically tested by observation. They should also unite a wide variety of previously disconnected facts, should be testable and falsifiable against observed data, and should provide abundant avenues for future research.

The Darwinian approach should not be confused with superficially persuasive ad hoc explanations about the holistic interactions that appear to control the regimes of watershed behavior, but do not offer explanations for their origins, or do not provide independent evidence of causation. The ability of regionalization techniques to predict the parameters of a hydrologic model or hydrologic properties (like the flood frequency distribution) is also not equivalent to explaining those variations in a "Darwinian" way. Darwin sought theories that not only predicted the patterns in the present spatial distribution of things but also connected that distribution to the historical processes that created them. It should also be obvious that a Darwinian "explanatory theory" is not simply a landscape evolution model (e.g., Willgoose et al., 1991; Dietrich et al., 2003; Pelletier et al., 2013) (though these have a role, as discussed above), nor is landform evolution the only type of landscape development that the Darwinian approach would consider. For instance, the work by Di Baldassarre et al. (2009) on the connection between contemporary flooding and historical floodplain development and management (see also Castellarin et al., 2010; Di Baldassarre et al., 2010) can be seen as following the "Darwinian" mold of seeking historical explanations for present-day variations. The classification of syndromes of water crises by Srinivasan et al. (2012) is based on common mechanisms of causation and could be regarded as "genetic" within the Darwinian framework.

The Darwinian approach does not automatically result in a predictive model that can be generalized across places. Such a model is not its purpose - Darwin was not, after all, concerned with making predictions about the future evolution of species. Rather, it leads to explanations for existing observations. However, where the observations are of a pattern in a population, and the explanation suggests a mechanism that creates that pattern, it may be possible to extrapolate and make predictions across the unobserved members of the population, and perhaps to make predictions about how the pattern will change in the future. Such predictions are in character conditional and statistical: they posit that under certain conditions (corals growing around an island being actively uplifted), some outcomes (fringing reefs) are more likely than others (coral atolls). The predictions made by such a theory are probabilistic in a mode similar to statistical mechanics but operate on far smaller populations subject to a more complex set of conditions than an ideal gas, and are thus much more prone to unforeseeable deviations from the central tendency.

A similar argument was put forward by Leopold (1994) in a largely overlooked paper titled "River morphology as an analog to Darwin's theory of natural selection." He compared the members of a species to the reaches along a river as members of a population. These, he suggested, share the properties that (1) the individuals are not identical to one another (as, say, electrons are) but rather have variable properties; (2) they are not members of a type, but a variable population, whose variability is always renewed, and whose mean properties shift gradually in time; (3) each member is a product of its history, and carries the marks of that history with it; and (4) each exhibits goal-directed (teleonomic) behavior, (5) this goal directedness being the consequence of natural laws and the laws of probability played out over time in a population of systems able to retain the physical imprint of the past. Leopold (1994) also argued that fluvial geomorphologists at the time had little capacity to explain the geometry of rivers - as we have argued hydrologists have little capacity to explain the hydrology of watersheds - though there have been great advances in that area since. We have here avoided discussion of teleology and teleonomy for fear that it would mire the discussion in semantics - but we would refer an interested reader to Leopold (1994), and to the essay by Mayr (1982) that it draws inspiration from.

Darwinian theories could also find practical application where they can constrain the combination of watershed properties and hydrologic behavior likely to occur in an area. There is currently no basis in well-tested theory for deciding whether a parameterized watershed model represents a watershed that could plausibly have evolved or for deciding the probability that it would do so. This concept might be given a more formal definition. Consider the historical watershed evolution as a trajectory in "landscape space", with each point along this trajectory mapping to a behavioral subset of the "model space" of the system at a point in time (Beven, 2002). In control systems theory, subspaces of the state space of a dynamical system are defined as "reachable" if there exists a control input that can move the system from an initial condition into them. In the language of Bayesian approaches to model uncertainty, the prior distributions of watershed model parameters are not constrained by the reachability of the model subspaces they represent. Such additional constraints might be of some use in modeling applications.

\subsection{You may already be a Darwinian!}

Elements of the Darwinian approach to hydrology can be found in the studies cited above and in many other works not cited. These works variously contribute to the characterization of the hydrologic anatomy and physiology in the sense of hydrologic regimes, filtering, and functional patterns; understanding of the mechanisms that shape the hydrologic properties of landscapes through time; classification and analysis of the patterns of variation in watersheds in space; and a large number of highly characterized experimental watersheds, each of which has been studied largely independently of the others. These efforts have, however, not been coordinated, and the links between them have yet to be 
made in many cases. There also appears to be only limited linkage between insights from paleohydrology - the "fossil remains" of past hydrologic regimes (Baker, 2013b) - and contemporary watershed hydrology. A deeper understanding may come when the connections between these individual studies are investigated in a coordinated way.

The "Darwinian" approach described here includes or extends many of the suggestions of McDonnell et al. (2007). It echoes the call to understand "why" the heterogeneity and structure of watersheds exist, and to link this understanding to observable "functional traits" and watershed function. In contrast, however, the Darwinian approach suggests that this understanding can be obtained by investigating the processes of historical development and change that give rise to the heterogeneity rather than focusing solely on the contemporary properties and behavior. We also advocate for an approach to classification that aims to unify genotypic and phenotypic approaches. The search for scaling and emergent behavior, including network and optimality principles, is compatible with a Darwinian approach that seeks to explain the origin of these patterns in the processes that create them. These theories are complementary: a proposed optimality theory for hydrology will gain in credibility and usefulness if the historical progression that gives rise to it can be explained and used to define the set of watersheds where it will likely apply.

Acknowledgements. This paper and its authors have benefited greatly from many long discussions with Murugesu Sivapalan over many years about Darwinian and other approaches to hydrology. We also wish to thank and acknowledge Kathleen Lohse and Anne Jefferson for many interesting discussions contributing to this work. We would like to thank Ashley Ball for her constructive review of a draft manuscript. We are indebted to our reviewers Boris Schröder, Martijn Westhoff, and especially Vic Baker for their thoughtful reviews and comments. V. R. Baker's review is itself a worthwhile overview of salient aspects of the philosophy of science, and we have drawn from the extensive references he provided to improve the manuscript. This research was supported by the Critical Zone Observatory (NSF JRB-SCM CZO - EAR 0724958), National Science Foundation EAR 0910666 (University of Arizona) and EAR 0911205 (University of Illinois UrbanaChampaign).

Edited by: A. Kleidon

\section{References}

Atkinson, S. E.: Climate and landscape controls on water balance model complexity over changing timescales, Water Resour. Res., 38, 1314, doi:10.1029/2002WR001487, 2002.

Ayala, F. J.: Darwin and the scientific method, P. Natl. Acad. Sci., 106, 10033-10039, doi:10.1073/pnas.0901404106, 2009.
Bain, D. J., Green, M. B., Campbell, J. L., Chamblee, J. F., Chaoka, S., Fraterrigo, J. M., Kaushal, S. S., Martin, S. L., Jordan, T. E., Parolari, A. J., Sobczak, W. V., Weller, D. E., Wollheim, W. M., Boose, E. R., Duncan, J. M., Gettel, G. M., Hall, B. R., Kumar, P., Thompson, J. R., Vose, J. M., Elliott, E. M., and Leigh, D. S.: Legacy Effects in Material Flux: Structural Catchment Changes Predate Long-Term Studies, Bioscience, 62, 575-584, doi:10.1525/bio.2012.62.6.8, 2012.

Baker, V. R.: Hypotheses and geomorphological reasoning, in: The scientific Nature of Geomorphology, edited by: Rhoads, B. L. and Thorn, C. E., Wiley, New York, 57-85, 1996a.

Baker, V. R.: Discovering the Future in the Past: Palaeohydrology and Geomorphological Change, in: Global Continental Changes: The Context of Palaeohydrology, edited by: Branson, J., Brown, A. G., and Gregory, K. T., The Geological Society of London Special Publication No. 115, Geologiceal Society of London, London, 73-83, 1996b.

Baker, V. R.: Paleohydrology and the hydrological sciences, in: Palaeohydrology and Environmental Change, edited by: Baker, V. R. and Gregory, K. J., J. Wiley \& Sons, Chichester, 1-10, 1998.

Baker, V. R.: Geosemiosis, Geol. Soc. Am. Bull., 111, 633-646, 1999.

Baker, V. R.: Conversing with the Earth: The geological approach to understanding, in: Earth Matters: The Earth Sciences, Philosophy, and the Claims of Community, edited by: Frodeman, R., Prentice-Hall, New Jersey, 1-10, 2000.

Baker, V. R.: Palaeoflood hydrology in a global context, Catena, 66, 161-168, 2006.

Baker, V. R.: Paleoflood hydrology: origin, progress, prospects, $\mathrm{Ge}-$ omorphology, 101, 1-13, 2008.

Baker, V. R.: Terrestrial analogues, planetary geology, and the nature of geological reasoning, Planet. Space Sci., doi:10.1016/j.pss.2012.10.008, in press, 2012.

Baker, V. R.: Global late Quaternary fluvial paleohydrology with special emphasis on paleofloods and megafloods, in: Fluvial Geomorphology, edited by: Wohl, E. E., Vol. 9, Treatise on Geomorphology, Academic Press, San Diego, 511-527, 2013a.

Baker, V. R.: Interactive comment on "Darwinian hydrology: can the methodology Charles Darwin pioneered help hydrologic science?" by C. Harman and P. A. Troch, Hydrol. Earth Syst. Sci. Discuss., 10, C3324-C3325, 2013b.

Benito, G. and Thorndycraft, V. R. (Eds.): Systematic, Palaeoflood and Historical Data for the Improvement of Flood Risk Estimation: A Methodological Guide, Centro de Ciencias Medioambientales, Madrid, 2004.

Beven, K. J.: Uniqueness of place and process representations in hydrological modelling, Hydrol. Earth Syst. Sci., 4, 203-213, doi:10.5194/hess-4-203-2000, 2000.

Beven, K.: Towards a coherent philosophy for modelling the environment, P. Roy. Soc. A, 458, 2465-2484, doi:10.1098/rspa.2002.0986, 2002.

Beven, K.: Searching for the Holy Grail of scientific hydrology: $Q_{t}=(S, R, \Delta t) A$ as closure, Hydrol. Earth Syst. Sci., 10, 609618, doi:10.5194/hess-10-609-2006, 2006.

Bloschl, G. and Zehe, E.: On hydrological predictability, Hydrol. Process., 19, 3923-3929, doi:10.1002/hyp.6075, 2005.

Brunsden, D. and Thornes, J. B.: Landscape sensitivity and change, T. Inst. British Geogr., 463-484, 1979. 
Brutsaert, W.: Hydrology: An Introduction, Cambridge University Press, 2005.

Budyko, M. I.: Climate and Life, Academic Press, New York, p. $508,1974$.

Carrillo, G., Troch, P. A., Sivapalan, M., Wagener, T., Harman, C., and Sawicz, K.: Catchment classification: hydrological analysis of catchment behavior through process-based modeling along a climate gradient, Hydrol. Earth Syst. Sci., 15, 3411-3430, doi:10.5194/hess-15-3411-2011, 2011.

Castellarin, A., Di Baldassarre, G., and Brath, A.: Floodplain management strategies for flood attenuation in the river Po, River Res. Appl., 27, 1037-1047, doi:10.1002/rra.1405, 2010.

Chamberlin, T. C.: The method of multiple working hypotheses, Science, 15, 92-96, 1890.

Cheng, L., Yaeger, M., Viglione, A., Coopersmith, E., Ye, S., and Sivapalan, M.: Exploring the physical controls of regional patterns of flow duration curves - Part 1: Insights from statistical analyses, Hydrol. Earth Syst. Sci., 16, 4435-4446, doi:10.5194/hess-16-4435-2012, 2012.

Cleland, C. E.: Methodological and epistemic differences between historical science and experimental science, Philos. Sci., 69, 474-496, 2002.

Cleland, C. E.: Prediction and explanation in historical natural science, British J. Philos. Sci., 62, 551-582, 2011.

Cleland, C. E.: Common cause explanation and the search for a smoking gun, in: Rethinking the Fabric of Geology, edited by: Baker, V. R., Geological Society of America Special Paper 502, Geological Society of America, Boulder, Colorado, 502, 1-9, 2013.

Coopersmith, E., Yaeger, M. A., Ye, S., Cheng, L., and Sivapalan, M.: Exploring the physical controls of regional patterns of flow duration curves - Part 3: A catchment classification system based on regime curve indicators, Hydrol. Earth Syst. Sci., 16, 44674482, doi:10.5194/hess-16-4467-2012, 2012.

Cullis, J. D. S., Gillis, C.-A., Bothwell, M. L., Kilroy, C., Packman, A., and Hassan, M.: A conceptual model for the blooming behavior and persistence of the benthic mat-forming diatom Didymosphenia geminatain oligotrophic streams, J. Geophys. Res., 117, G00N03, doi:10.1029/2011JG001891, 2012.

Darwin, C.: On the Structure and Distribution of Coral Reefs: Being the First Part of the Geology of the Voyage of the Beagle Under the Command of Captain Fitzroy, RN During the Years 1832 to 1836, Smith Elder and Co., London, 1842.

Darwin, C.: On the origins of species by means of natural selection, Murray, London, 1859.

Darwin, C.: The formation of vegetable mould, through the action of worms, with observations on their habits, John Murray, London, 1881 .

Deutsch, D.: A new way to explain explanation, available from: http://www.ted.com/talks/david_deutsch_a_new_way_to_ explain_explanation.html (last access: 2 February 2014), 2009.

De Waal, C.: Peirce: A Guide for the Perplexed, Bloomsbury Academic, New York, 2013.

Di Baldassarre, G., Castellarin, A., and Brath, A.: Analysis of the effects of levee heightening on flood propagation: example of the River Po, Italy, Hydrolog. Sci. J., 54, 1007-1017, doi:10.1623/hysj.54.6.1007, 2009.
Di Baldassarre, G., Montanari, A., Lins, H., Koutsoyiannis, D. Brandimarte, L., and Blöschl, G.: Flood fatalities in Africa: From diagnosis to mitigation, Geophys. Res. Lett., 37, L22402, doi:10.1029/2010GL045467, 2010.

Dietrich, W. E., Bellugi, D. G., Sklar, L. S., Stock, J. D., Heimsath, A. M., and Roering, J. J.: Geomorphic transport laws for predicting landscape form and dynamics, in: Prediction in Geomorphology, edited by: Wilcock, P. and Iverson, R. M., Geophysical Monograph 135, American Geophysical Union, Washington, D.C., 103-132, 2003.

Donohue, R. J., Roderick, M. L., and McVicar, T. R.: On the importance of including vegetation dynamics in Budyko's hydrological model, Hydrol. Earth Syst. Sci., 11, 983-995, doi:10.5194/hess11-983-2007, 2007.

Dunne, T.: Field studies of hillslope flow processes, in: Hillslope Hydrology, edited by: Kirkby, M. J., J. Wiley \& Sons, New York, NY, 227-293, 1978

Falkenmark, M. and Chapman, T. G.: Comparative hydrology: an ecological approach to land and water resources, Unesco, Paris, France, 1989.

Farmer, D., Sivapalan, M., and Jothityangkoon, C.: Climate, soil, and vegetation controls upon the variability of water balance in temperate and semiarid landscapes: Downward approach to water balance analysis, Water Resour. Res., 39, 1035, doi:10.1029/2001WR000328, 2003.

Frodeman, R. L.: Geological reasoning: Geology as an interpretive and historical science, Geol. Soc. Am. Bull., 107, 960-968, 1995.

Gentine, P., D’Odorico, P., Lintner, B. R., Sivandran, G., and Salvucci, G.: Interdependence of climate, soil, and vegetation as constrained by the Budyko curve, Geophys. Res. Lett., 39, L19404, doi:10.1029/2012GL053492, 2012.

Ghiselin, M. T.: The Triumph of the Darwinian Method, Dover Publications, Dover, 1969.

Gilbert, G. K.: The inculcation of scientific method by example, Am. J. Sci., 31, 284-299, 1886.

Gilbert, G. K.: The origin of hypotheses illustrated by the discussion of a topographic problem, Science, 2, 1-13, 1896.

Godfrey-Smith, P.: Theory and Reality: An Introduction to the Philosophy of Science, University of Chicago Press, Chicago, 2003.

Gould, S. J.: Worm for a Century, and All Seasons, in: Hen's Teeth and Horse's Toes, W. W. Norton \& Company, New York, NY, p. 413,1983 .

Gould, S. J. and Eldredge, N.: Punctuated equilibrium comes of age, Nature, 366, 223-227, 1993.

Grimm, V., Revilla, E., Berger, U., Jeltsch, F., Mooij, W. M., Railsback, S. F., Thulke, H.-H., Weiner, J., Wiegand, T., and De Angelis, D. L.: Pattern-oriented modeling of agent-based complex systems: lessons from ecology, Science, 310, 987-991, 2005.

Guan, K., Thompson, S. E., Harman, C. J., Basu, N. B., Rao, P. S. C., Sivapalan, M., Packman, A. I., and Kalita, P. K.: Spatiotemporal scaling of hydrological and agrochemical export dynamics in a tile-drained Midwestern watershed, Water Resour. Res., 47, W00J02, doi:10.1029/2010WR009997, 2011.

Hancock, G. R., Evans, K. G., Mcdonnell, J., and Hopp, L.: Ecohydrological controls on soil erosion and landscape evolution, Ecohydrology, 5, 478-490, doi:10.1002/eco.241, 2011. 
Harman, C. J., Troch, P. A., and Sivapalan, M.: Functional model of water balance variability at the catchment scale: 2 . Elasticity of fast and slow runoff components to precipitation change in the continental United States, Water Resour. Res., 47, W02523, doi:10.1029/2010WR009656, 2011.

Harte, J.: Toward a synthesis of the Newtonian and Darwinian worldviews, Phys. Today, 55, 29, doi:10.1063/1.1522164, 2002.

Heimsath, A. M., Furbish, D. J., and Dietrich, W. E.: The illusion of diffusion: Field evidence for depth-dependent sediment transport, Geology, 33, 949-952, doi:10.1130/G21868.1, 2005.

Heimsath, A. M., Dietrich, W. E., Nishiizumi, K., and Finkel, R. C.: The soil production function and landscape equilibrium, Nature, 388, 358-361, 1997.

Hopp, L., Harman, C., Desilets, S. L. E., Graham, C. B., McDonnell, J. J., and Troch, P. A.: Hillslope hydrology under glass: confronting fundamental questions of soil-water-biota coevolution at Biosphere 2, Hydrol. Earth Syst. Sci., 13, 2105 2118, doi:10.5194/hess-13-2105-2009, 2009.

House, P. K., Webb, R. H., Baker, V. R., and Levish, D. (Eds.): Ancient Floods, Modern Hazards: Principles and Applications of Paleoflood Hydrology, Water Science and Applications 5, American Geophysical Union, Washington, D.C., 2002.

Jackson, C.: [Review of] The Structure and Distribution of Coral Reefs: Being the First Part of the Geology of the Voyage of the 'Beagle', under the Command of Capt. Fitzroy, R. N., during the Years 1832 to 1836, J. Roy. Geogr. Soc. Lond., 12, 115-120, 1842.

Jefferson, A., Grant, G. E., Lewis, S. L., and Lancaster, S. T.: Coevolution of hydrology and topography on a basalt landscape in the Oregon Cascade Range, USA, Earth Surf. Proc. Land., 35, 803-816, doi:10.1002/esp.1976, 2010.

Jothityangkoon, C. and Sivapalan, M.: Framework for exploration of climatic and landscape controls on catchment water balance, with emphasis on inter-annual variability, J. Hydrol., 371, 154168, doi:10.1016/j.jhydrol.2009.03.030, 2009.

King, E. G. and Caylor, K. K.: Ecohydrology in practice: strengths, conveniences, and opportunities, edited by: Krause, S., Hannah, D. M., Sadler, J. P., and Wood, P. J., Ecohydrology, 4, 608-612, doi:10.1002/eco.248, 2011.

Kirchner, J. W.: Getting the right answers for the right reasons: Linking measurements, analyses, and models to advance the science of hydrology, Water Resour. Res., 42, W03S04, doi:10.1029/2005WR004362, 2006.

Kirchner, J. W.: Catchments as simple dynamical systems: Catchment characterization, rainfall-runoff modeling, and doing hydrology backward, Water Resour. Res., 45, W02429, doi:10.1029/2008WR006912, 2009.

Kleidon, A. and Schymanski, S.: Thermodynamics and optimality of the water budget on land: A review, Geophys. Res. Lett., 35, L20404, doi:10.1029/2008GL035393, 2008.

Kleinhans, M. G., Bierkens, M. F. P., and van der Perk, M.: HESS Opinions On the use of laboratory experimentation: "Hydrologists, bring out shovels and garden hoses and hit the dirt", Hydrol. Earth Syst. Sci., 14, 369-382, doi:10.5194/hess-14-3692010, 2010.

Klemeš, V.: Conceptualization and scale in hydrology, Remote Sens. Environ., 65, 1-23, doi:10.1016/0022-1694(83)90208-1, 1983.
Kumar, P.: Typology of hydrologic predictability, Water Resour. Res., 47, W00H05, doi:10.1029/2010WR009769, 2011.

Lavorel, S. and Garnier, E.: Predicting changes in community composition and ecosystem functioning from plant traits: revisiting the Holy Grail, Funct. Ecol., 16, 545-556, 2002.

Leopold, L. B.: River morphology as an analog to Darwin's theory of natural selection, P. Am. Philos. Soc., 138, 31-47, 1994.

Loague, K., Heppner, C. S., Ebel, B. A., and Vanderkwaak, J. E.: The quixotic search for a comprehensive understanding of hydrologic response at the surface: Horton, Dunne, Dunton, and the role of concept-development simulation, Hydrol. Process., 2505, 2499-2505, doi:10.1002/hyp.7834, 2010.

Lohse, K. A.: Hydrological and Biogeochemical Controls on Nitrogen Losses from Tropical Forests: Responses to Anthropogenic Nitrogen Additions, University of California, Berkeley, 1-250, 17 November 2002

Lohse, K. A. and Dietrich, W. E.: Contrasting effects of soil development on hydrological properties and flow paths, Water Resour. Res., 41, W12419, doi:10.1029/2004WR003403, 2005.

Lyell, C.: Principles of Geology, John Murray, London, 1830.

Magilligan, F. J. and Nislow, K. H.: Changes in hydrologic regime by dams, Geomorphology, 71, 61-78, doi:10.1016/j.geomorph.2004.08.017, 2005.

Mayr, E.: The Growth of Biological Thought: Diversity, Evolution, and Inheritance, Harvard University Press, Cambridge, MA, 1982.

McDonnell, J. J. and Woods, R.: On the need for catchment classification, J. Hydrol., 299, 2-3, 2004.

McDonnell, J. J., Sivapalan, M., Vaché, K., Dunn, S., Grant, G., Haggerty, R., Hinz, C., Hooper, R., Kirchner, J., Roderick, M. L., Selker, J., and Weiler, M.: Moving beyond heterogeneity and process complexity: A new vision for watershed hydrology, Water Resour. Res., 43, W07301, doi:10.1029/2006WR005467, 2007.

McNamara, J. P., Tetzlaff, D., Bishop, K., Soulsby, C., Seyfried, M., Peters, N. E., Aulenbach, B. T., and Hooper, R.: Storage as a Metric of Catchment Comparison, edited by: Pelto, M. S. and Kelly, R. E., Hydrol. Process., 25, 3364-3371, doi:10.1002/hyp.8113.

Milly, P. C. D.: Climate, interseasonal storage of soil water, and the annual water balance, Adv. Water Resour., 17, 19-24, doi:10.1016/0309-1708(94)90020-5, 1994.

Mosley, M. P.: Delimitation of New Zealand hydrologic regions, Remote Sens. Environ., 49, 173-192, doi:10.1016/00221694(81)90211-0, 1981.

Newman, B. D., Wilcox, B. P., Archer, S. R., Breshears, D. D., Dahm, C. N., Duffy, C. J., McDowell, N. G., Phillips, F. M., Scanlon, B. R., and Vivoni, E. R.: Ecohydrology of waterlimited environments: A scientific vision, Water Resour. Res., 42, W06302, doi:10.1029/2005WR004141, 2006.

Paola, C., Foufoula-Georgiou, E., Dietrich, W. E., Hondzo, M., Mohrig, D., Parker, G., Power, M. E., Rodriguez-Iturbe, I., Voller, V., and Wilcock, P.: Toward a unified science of the Earth's surface: opportunities for synthesis among hydrology, geomorphology, geochemistry, and ecology, Water Resour. Res., 42, W03S10, doi:10.1029/2005WR004336, 2006.

Pelletier, J. D. and Rasmussen, C.: Geomorphically based predictive mapping of soil thickness in upland watersheds, Water Resour. Res., 45, 1-15, doi:10.1029/2008WR007319, 2009. 
Pelletier, J. D., Barron-Gafford, G. A., Breshears, D. D., Brooks, P. D., Chorover, J., Durcik, M., Harman, C. J., Huxman, T. E., Lohse, K. A., Lybrand, R., Meixner, T., McIntosh, J. C., Papuga, S. A., Rasmussen, C., Schaap, M., Swetnam, T. L., and Troch, P. A.: Coevolution of nonlinear trends in vegetation, soils, and topography with elevation and slope aspect: A case study in the sky islands of southern Arizona, J. Geophys. Res.-Earth, 118, 741-758, doi:10.1002/jgrf.20046, 2013.

Pickup, G. and Warner, R. F.: Effects of hydrologic regime on magnitude and frequency of dominant discharge, Remote Sens. Environ., 29, 51-75, doi:10.1016/0022-1694(76)90005-6, 1976.

Porporato, A., Daly, E., and Rodriguez-Iturbe, I.: Soil Water Balance and Ecosystem Response to Climate Change, Am. Natural., 164, 625-632, doi:10.1086/424970, 2004.

Robinson, J. S. and Sivapalan, M.: Temporal scales and hydrological regimes: Implications for flood frequency scaling, Water Resour. Res., 33, 2981-2999, 1997.

Roering, J. J.: How well can hillslope evolution models "explain" topography? Simulating soil transport and production with highresolution topographic data, Geol. Soc. Am. Bull., 120, 12481262, doi:10.1130/B26283.1, 2008.

Roering, J. J., Kirchner, J. W., and Dietrich, W. E.: Evidence for nonlinear, diffusive sediment transport on hillslopes and implications for landscape morphology, Water Resour. Res., 35, 853870, 1999.

Ruse, M.: Darwin's debt to philosophy: An examination of the influence of the philosophical ideas of John . W. Herschel and William Whewell on the development of Charles Darwin's theory of evolution, Stud. Hist. Philos. Sci. A, 6, 159-181, 1975.

Sawicz, K., Wagener, T., Sivapalan, M., Troch, P. A., and Carrillo, G.: Catchment classification: empirical analysis of hydrologic similarity based on catchment function in the eastern USA, Hydrol. Earth Syst. Sci., 15, 2895-2911, doi:10.5194/hess-15-28952011, 2011.

Schröder, B.: Pattern, process, and function in landscape ecology and catchment hydrology - how can quantitative landscape ecology support predictions in ungauged basins?, Hydrol. Earth Syst. Sci., 10, 967-979, doi:10.5194/hess-10-967-2006, 2006.

Schumm, S. A.: Paleohydrology, application of modern hydrologic data to problems of the ancient past, International Hydrology Symposium, Proceedings Volume 1, Ft. Collins, Colorado, 185193, 1967.

Schumm, S. A.: To Interpret the Earth: Ten Ways to be Wrong, Cambridge University Press, Cambridge, 1991.

Schymanski, S. J.: Optimality as a Concept to Understand and Model Vegetation at Different Scales, Geography Compass, 2, 1580-1598, doi:10.1111/j.1749-8198.2008.00137.x, 2008.

Schymanski, S. J., Sivapalan, M., Roderick, M. L., Hutley, L. B., and Beringer, J.: An optimality-based model of the dynamic feedbacks between natural vegetation and the water balance, Water Resour. Res., 45, 1-18, doi:10.1029/2008WR006841, 2009.

Sivapalan, M.: Prediction in ungauged basins: a grand challenge for theoretical hydrology, Hydrol. Process., 17, 3163-3170, doi:10.1002/hyp.5155, 2003.

Sivapalan, M.: Pattern, Process and Function: Elements of a Unified Theory of Hydrology at the Catchment Scale, in: Encyclopedia of Hydrological Sciences, edited by: Anderson, M. G., John Wiley \& Sons, Ltd., New York, NY, 193-219, 2005.
Sivapalan, M.: Predictions Under Change: Water, Earth and Biota in the Anthropocene, Research Report, Center for Water as a Complex Ecosystem, available at: http://cwaces.geog.illinois.edu/ synthesis/reports/documents/AppendixE-PUCDraftReport.pdf (last access: 2 February 2014), 2012.

Sivapalan, M., Blöschl, G., Zhang, L., and Vertessy, R.: Downward approach to hydrological prediction, Hydrol. Process., 17, 21012111, doi:10.1002/hyp.1425, 2003.

Sivapalan, M., Yaeger, M. A., Harman, C. J., Xu, X., and Troch, P. A.: Functional model of water balance variability at the catchment scale: 1. Evidence of hydrologic similarity and space-time symmetry, Water Resour. Res., 47, W02522, doi:10.1029/2010WR009568, 2011a.

Sivapalan, M., Thompson, S. E., Harman, C. J., Basu, N. B., and Kumar, P.: Water cycle dynamics in a changing environment: Improving predictability through synthesis, Water Resour. Res., 47, W00J01, doi:10.1029/2011WR011377, 2011b.

Srinivasan, V., Lambin, E. F., Gorelick, S. M., Thompson, B. H., and Rozelle, S.: The nature and causes of the global water crisis: Syndromes from a meta-analysis of coupled human-water studies, Water Resour. Res., 48, W10516, doi:10.1029/2011WR011087, 2012.

Suding, K. N. and Goldstein, L. J.: Testing the Holy Grail framework: using functional traits to predict ecosystem change, New Phytol., 180, 559-562, doi:10.1111/j.1469-8137.2008.02650.x, 2008.

Tetzlaff, D., McNamara, J. P., and Carey, S. K.: Measurements and modelling of storage dynamics across scales, edited by: Tetzlaff, D., Carey, S., and McNamara, J., Hydrol. Process., 3835, 38313835, doi:10.1002/hyp.8396, 2011.

Thagard, P. R.: Discussion: Darwin and Whewell, Stud. Hist. Philos. Sci. A, 8, 353-356, 1977.

Thompson, S. E., Harman, C. J., Konings, A. G., Sivapalan, M., Neal, A., and Troch, P. A.: Comparative hydrology across AmeriFlux sites: The variable roles of climate, vegetation, and groundwater, Water Resour. Res., 47, W00J07, doi:10.1029/2010WR009797, 2011.

Thompson, S. E., Sivapalan, M., Harman, C. J., Srinivasan, V., Hipsey, M. R., Reed, P., Montanari, A., and Blöschl, G.: Developing predictive insight into changing water systems: useinspired hydrologic science for the Anthropocene, Hydrol. Earth Syst. Sci., 17, 5013-5039, doi:10.5194/hess-17-50132013, 2013.

Troch, P. A., Martinez, G. F., Pauwels, V. R. N., Durcik, M., Sivapalan, M., Harman, C., Brooks, P. D., Gupta, H., and Huxman, T. Climate and vegetation water use efficiency at catchment scales, Hydrol. Process., 23, 2409-2414, doi:10.1002/hyp.7358, 2009.

Troch, P. A., Carrillo, G., Sivapalan, M., Wagener, T., and Sawicz, K.: Climate-vegetation-soil interactions and long-term hydrologic partitioning: signatures of catchment co-evolution, Hydrol. Earth Syst. Sci., 17, 2209-2217, doi:10.5194/hess-17-22092013, 2013.

Tucker, G. E. and Hancock, G. R.: Modelling landscape evolution, Earth Surf. Proc. Land., 35, 28-50, doi:10.1002/esp.1952, 2010.

Von Engelhardt, W. and Zimmerman, J.: Theory of Earth Science, Cambridge University Press, Cambridge, 1988.

Wagener, T., Sivapalan, M., Troch, P. A., and Woods, R.: Catchment classification and hydrologic similarity, Geography Compass, 1, 901-931, doi:10.1111/j.1749-8198.2007.00039.x, 2007. 
Wagener, T., Sivapalan, M., Troch, P. A., McGlynn, B. L., Harman, C. J., Gupta, H. V., Kumar, P., Rao, P. S. C., Basu, N. B., and Wilson, J. S.: The future of hydrology: An evolving science for a changing world, Water Resour. Res., 46, 1-10, doi:10.1029/2009WR008906, 2010.

Wagener, T., Blöschl, G., Goodrich, D. C., Gupta, H., Sivapalan, M., Tachikawa, Y., Troch, P. A., and Weiler, M.: A synthesis framework for runoff prediction in ungauged basins, in: Runoff Prediction in Ungauged Basins: Synthesis across Processes, Places and Scales, edited by: Blöschl, G., Sivapalan, M., Wagener, T., Viglione, A., and Savenije, H. H. G., Cambridge University Press, 11-28, 2013.

Western, A. and Grayson, R.: Soil Moisture and Runoff Processes at Tarrawarra, in: Spatial patterns in catchment hydrology: observations and modelling, edited by: Grayson, R. B. and Blöschl, G., Cambridge University Press, 209-246, 2001.

Willgoose, G., Bras, R. L., and Rodriguez-iturbe, I.: A coupled channel network growth and hillslope evolution model: 1 . Theory, Water Resour. Res., 27, 1671-1684, 1991.

Winter, T. C.: The concept of hydrologic landscapes, J. Am. Water Resour. Assoc., 37, 335-349, doi:10.1111/j.17521688.2001.tb00973.x, 2001.

Wittenberg, H.: Baseflow recession and recharge as nonlinear storage processes, Hydrol. Process., 13, 715-726, 1999.

Wittenberg, H.: Effects of season and man-made changes on baseflow and flow recession: case studies, Hydrol. Process., 17, 2113-2123, doi:10.1002/hyp.1324, 2003.
Woods, R.: The impact of spatial scale on spatial variability in hydrologic response: experiments and ideas, in: Scales in hydrology and water management, vol. IAHS Publ. 287, edited by: Tchiguirinskaia, I., Bonell, M., and Hubert, P., IAHS Press, Wallingford UK, 2004.

Yaeger, M., Coopersmith, E., Ye, S., Cheng, L., Viglione, A., and Sivapalan, M.: Exploring the physical controls of regional patterns of flow duration curves - Part 4: A synthesis of empirical analysis, process modeling and catchment classification, Hydrol. Earth Syst. Sci., 16, 4483-4498, doi:10.5194/hess-16-44832012, 2012.

Ye, S., Yaeger, M., Coopersmith, E., Cheng, L., and Sivapalan, M.: Exploring the physical controls of regional patterns of flow duration curves - Part 2: Role of seasonality, the regime curve, and associated process controls, Hydrol. Earth Syst. Sci., 16, 44474465, doi:10.5194/hess-16-4447-2012, 2012.

Yokoo, Y., Sivapalan, M., and Oki, T.: Investigating the roles of climate seasonality and landscape characteristics on mean annual and monthly water balances, J. Hydrol., 357, 255-269, doi:10.1016/j.jhydrol.2008.05.010, 2008.

Zhang, L., Dawes, W. R., and Walker, G. R.: Response of mean annual evapotranspiration to vegetation changes at catchment scale, Water Resour. Res., 37, 701-708, 2001. 